\title{
Evaluation of Selection Indices in Screening Durum Wheat Genotypes Combining Drought Tolerance and High Yield Potential
}

\author{
J.M. Patel ${ }^{1 *}$, A.S. Patel ${ }^{1}$, C.R. Patel ${ }^{1}$, H.M. Mamrutha ${ }^{2}$, \\ Sharma Pradeep ${ }^{2}$ and Karen P. Pachchigar ${ }^{1}$ \\ ${ }^{1}$ Wheat Research Station, S.D Agricultural University, Vijapur -382 870, India \\ ${ }^{2}$ ICAR-Indian Institute of Wheat and Barley Research (IIWBR), Karnal, India \\ *Corresponding author
}

\section{Keywords}

Stress intensity, Grain yield,

Moisture stress indices, Durum wheat

Article Info

Accepted:

10 March 2019

Available Online:

10 April 2019

\section{A B S T R A C T}

In order to investigate the relationships among the drought tolerance/resistance indices an experiment was conducted in alpha lattice design with two replications under two moisture regimes during the crop season 2015-16. Thirteen indices, which were most frequently used in plant breeding, were compared based on grain yield of 20 durum wheat genotypes. Highly significant differences for yield ( $\mathrm{Yp}$ and $\mathrm{Ys}$ ) and all drought tolerance indices except TOL were observed which indicated that genotypes were differing for genes controlling yield and drought tolerance indices. The mean of grain yield under non stress condition (Yp) values ranged between 4.60(BIJAGA RED) to 20.53 (g/plant) (MP 1279), whereas under stress condition (Ys) yield range was found between 2.32(N 59) to 8.67 g/plant (MP 1279). It is remarkable that the genotypes MP 1279 and DWR 185 and CG 1010 had high performances in both stressed and non-stressed conditions for grain yield. The grain yield reduction was ranged between 12.58 to 76.18 per cent in drought plots. The average reduction in grain yield due to drought stress was 58 per cent. This explains the massive reduction in yield under severe drought stress for majority of genotypes. Therefore, moderate drought stress environments are more preferable as compared to severe drought stress to identify drought tolerant lines. STI-related indices (K1STI and K2STI) were found convenient parameters to select high-yielding genotypes in both stress and non-stress conditions. The MP, GMP and YI indices, which were highly positively and significantly correlated to the grain yields in both favorable and drought stress environments, were introduced as the best indices. Significant and positive correlation of $\mathrm{Yp}$ and $\mathrm{Ys}(\mathrm{r}=0.68 \mathrm{p}<0.05)$ was found which indicates that high yield performance under favorable condition resulted in relatively high yield under stress conditions. Both Yp and Ys were significantly and positively correlated $(\mathrm{P}<0.05)$ with, MP $(\mathrm{r}=0.96$ and 0.84$)$, GMP $(\mathrm{r}=0.96$ and 0.83$), \mathrm{HM}(\mathrm{r}=0.83$ and 0.97$), \mathrm{YI}(\mathrm{r}=0.68$ and 1.00$), \mathrm{K} 1 \mathrm{STI}(\mathrm{r}=0.72$ and 0.63$)$ and K2-STI ( $\mathrm{r}=0.73$ and 0.98 ). This indicates that these indices were more effective in identifying high yielding lines under drought stress as well as non-stress conditions

\section{Introduction}

Wheat is one of the most important crops for food security worldwide (Bishaw et al., 2011;
Travlos, 2012). It is a foremost staple food crop of India and plays a vital role for stability of country's economy and people's food requirement. It has been grown in a wide 
range of arid and semi-arid areas, where drought occurs frequently because of rainfall fluctuations in rain-fed regions (Mardeh et al., 2006), and water scarcity in irrigated regions. Drought is a major constraint decreasing yield and potential production. Plant growth and productivity are adversely affected by water stress leading to heavy yield losses. Besides the water scarcity status, the exploration of new ways for an efficient use of water input is primordial for food security and sustainable environment. Breeding is one of the most efficient options to overcome this complex stress through the development of new varieties adapted to drought and climate instability. Therefore, selection of wheat genotypes should be adapted to drought stress. In addition, drought tolerance mechanism should be identified during the development of new cultivars in order to increase the productivity (Rajaram et al., 1996). Shortage of water has remained as a consistent problem for the farmers over past few years and different agronomic techniques have been introduced into the limelight The relative yield performance of genotypes in drought-stressed and favorable environments seems to be a common starting point for the identification of desirable genotypes for unpredictable rainfed conditions (Mohammadi et al., 2011). Evaluating performance of bread wheat lines and predicting drought tolerance is an essential part of the breeding process. Drought resistance is defined by Hall (1993) as the relative yield of a genotype compared to other genotypes subjected to the same drought stress. The ability of wheat varieties to execute reasonably well under variable water stress is an important trait for production stability under water stress conditions (Pirayvatlou, 2001). For effective breeding of drought tolerant wheat varieties good selection criteria is needed to identify the drought tolerant wheat genotypes. Despite the lack of understanding of the drought tolerance mechanisms, the grain yield remains the basis of genotypes selection for improving drought tolerance (Talebi et al., 2009; Farshadfar et al., 2012a). Some researchers believe in selection based on only favorable conditions where the low magnitude genotype $\times$ environment interaction permits to express the genetic potential yield (Richards, 1996; Rajaram and Van Ginkle, 2001); or only under stress conditions (Gavuzzi et al., 1997). However, high potential yield under nonstress conditions does not necessarily result in improved yield under stress conditions and genotypes with high yield may not be stress tolerant to drought and the reverse is true (Sio-Se Mardeh et al., 2006). Currently, many authors have chosen a mid-point and believe that selection considering yield under both non-stress and stress conditions is more efficient especially under unpredictable rainfed conditions with various yearly drought scenarios (Moosavi et al., 2008; Mohammadi et al., 2010; Farshadfar et al., 2012a, b, 2014). Thus, many drought indices have been proposed for screening drought tolerant genotypes based on yield under stressed and non-stressed environments (Mitra, 2001; Talebi et al., 2009; Mohammadi et al., 2010; Nouri et al., 2011) aiming at assisting the identification of stable, high yielding, drought tolerant genotypes: Stress susceptibility index (SSI) (Fischer and Maurer, 1978), drought response index (DRI) (Bidinger et al., 1987), relative drought index (RDI) (Fischer and Wood, 1979), mean productivity (MP), tolerance index (TOL) (Rosielle and Hamblin, 1981), yield stability index (YSI) (Bouslama and Schapaugh, 1984), geometric mean productivity (GMP), stress tolerance index (STI) (Fernandez, 1992), drought resistance index (DI) (Lan, 1998), modified stress tolerance indices 1 and 2 (MSTIk) (Farshadfar and Sutka, 2002), harmonic mean of yield (HM) (Dadbakhch et al., 2011), sensitivity drought index (SDI) (Farshadfar and Javadinia, 2011), and relative decrease in 
yield (RDY) (Farshadfar and Elyasi, 2012). The best indices are those which have high correlation with grain yield in both conditions and would be able to identify potential highr yielding and drought tolerant genotypes (Fernandez, 1992; Mitra, 2001; Farshadfar et al., 2001; Boussen et al., 2010).

In this perspective, the objectives of the study were to investigate the efficiency of drought selection indices to identify the best drought tolerant and high yielding genotypes adapted to both stressed and non-stressed conditions, study the inter-relationships among them and to identify the genotypes adapted to stressed environment.

\section{Materials and Methods}

Twenty durum wheat cultivars received from IIWBR, KARNAL were grown in two field experiments i.e., under water stress and irrigated conditions on $30^{\text {th }}$ November, 2015 at Wheat Research Station, Vijapur. The soil texture of experimental field was loamy sand with $\mathrm{pH}$ value 7.43 and EC $0.29 \mathrm{ds} \mathrm{m}^{-1}$.In case of water stress experiment, only pre sown irrigation was given for germination and later on no irrigation was applied up to maturity. While, four irrigations were applied at critical growth stages to the second experiment (irrigated). Genotypes in each experiment were planted in a alpha lattice design with two replications. As this design permit the analysis as per randomized complete block design with equal number of genotypes in all replications, analysis of variance was carried as per randomized complete block design. As noted by Barreto et al., (1994), in the field, an incomplete block design is indistinguishable from a randomized complete block design. Each experimental plot consisted of 4 rows keeping $10 \mathrm{~cm}$ distance within and $20 \mathrm{~cm}$ between rows. Centre's 8 plants were selected for recording the grain yield and agronomic traits. For statistical analysis grain yield was converted in to yield per plant. The whole dose of nutrients i.e. $\mathrm{N}_{2} 060 \mathrm{~kg} / \mathrm{ha}$ and $\mathrm{P}_{2} \mathrm{O}_{5} 30 \mathrm{~kg} / \mathrm{ha}$ was applied at the time of seedbed preparation in drought regime plots whereas in well watered plots $60 \mathrm{~kg} \mathrm{P}_{2} \mathrm{O}_{5}$ and $60 \mathrm{~kg}$. $\mathrm{N}_{2} 0$ was applied at the time of seedbed preparation and remaining $60 \mathrm{~kg}$. $\mathrm{N}_{2} 0$ was applied 21 days after sowing. In water stress experiment weeds were controlled manually (hoeing) but in irrigated experiment weeds were controlled by spraying the chemicals.

The drought tolerance indices were calculated as follows:

Stress susceptibility index (SSI) (Fisher \& Maurer, 1978): SSI = $1-\left(\mathrm{Y}_{\mathrm{S}} / \mathrm{Y}_{\mathrm{p}}\right) / \mathrm{SI}$, while $\mathrm{SI}=1-\left(\hat{\mathrm{Y}}_{\mathrm{s}} / \hat{\mathrm{Y}}_{\mathrm{p}}\right)$ Where as SI is stress intensity and $\hat{Y}_{s}$ and $\hat{Y}_{p}$ are the means of all genotypes under stress and well water conditions, respectively.

Tolerance index (TOL) and mean productivity (MP) as done by Rosielle and Hamblin (1981): TOL $=\left(\mathrm{Y}_{\mathrm{p}}-\mathrm{Y}_{\mathrm{s}}\right)$ and MP $=$ $\left(Y_{s}+Y_{p}\right) / 2 Y_{p}$ and $Y_{s}$ were the yield of each cultivars, non-stressed and stressed, respectively.

Yield Stability Index (YSI) (Bouslama \& Schapaugh, 1984): $\mathrm{YSI}=\mathrm{Y}_{\mathrm{s}} / \mathrm{Y}_{\mathrm{p}}$

Sensitivity drought index SDI=(Ypi - Ysi) / Ypi (Farshadfar and Javadinia, 2011)

Modified stress tolerance index (MSTI) as reported by Farshadfar and Sutka, (2002): MSTI $=\mathrm{k}_{\mathrm{i}} \mathrm{STI}$ while $\mathrm{k}_{1}=\left(\mathrm{Y}_{\mathrm{p}}^{2}\right) /\left(\hat{\mathrm{Y}}_{\mathrm{p}}{ }^{2}\right)$ and $\mathrm{k}_{2}$ $=\left(\mathrm{Y}_{\mathrm{s}}^{2}\right) /\left(\hat{\mathrm{Y}}_{\mathrm{s}}{ }^{2}\right)$ where $\mathrm{k}_{\mathrm{i}}$ is the correction coefficient.

Geometric mean productivity (GMP) and (Fernandez, 1992; Kristin et al., 1997): GMP $=\left(\mathrm{Y}_{\mathrm{p}} * \mathrm{Y}_{\mathrm{s}}\right)^{1 / 2} \mathrm{STI}=\left(\mathrm{Y}_{\mathrm{p}} * \mathrm{Y}_{\mathrm{s}}\right) /\left(\hat{\mathrm{Y}}_{\mathrm{p}}\right)^{2}$ 
Harmonic mean (HM) (Kristin et al., 1997): $\mathrm{HM}=2\left(\mathrm{Y}_{\mathrm{p}} * \mathrm{Y}_{\mathrm{s}}\right) /\left(\mathrm{Y}_{\mathrm{p}}+\mathrm{Y}_{\mathrm{s}}\right)$.

Yield Index (YI) YI $=\mathrm{Y}_{\mathrm{s}} / \hat{\mathrm{Y}}_{\mathrm{s}}($ Gavuzzi $e t$ al., 1997; Lin et al., 1986)

Stress Tolerance index $(\mathrm{STI})=(\mathrm{Ysi} \times \mathrm{x}$ Ypi $) /$ (Yp) ${ }^{2}$ Fernandez, 1992 Ys: Mean of grain yield under stressed; Yp: Mean of grain yield under non-stress conditions. $\mathrm{Y}_{\mathrm{si}}=$ Total mean (overall mean across genotypes) yield under stress condition

$\mathrm{Y}_{\mathrm{p} i}=$ Total mean (overall mean across genotypes) yield under normal condition

\section{Analysis of variance}

Analysis of variance was done for each index according to Steel \& Torrie (1980) by computer program MSTATC software. Genotypic correlations were determined by the method proposed by Johnson et al., (1955).

\section{Results and Discussion}

The analysis of variance showed highly significant differences for yield $\left(Y_{p}\right.$ and $\left.Y_{s}\right)$ and all drought tolerance indices (Table 1) except TOL, which indicated that genotypes were differing for genes controlling yield and drought tolerance indices (Golabdi et al., 2006; Gholipouri et al., 2009).

Stress Intensity: The overall stress intensity during year of experiment was 0.58 reflecting that yield reduction was about more than onehalf under stress conditions in comparison to yield under well irrigated conditions. The stress intensity index can take value between 0 and 1 . The larger value of stress intensity (SI) indicates more severe stress conditions (Dejan et al., 2008). The mean of Yp (g/plant) values ranged between 4.60 (BIJAGA RED) to 20.53 (MP 1279). Based on the YP, the genotypes MP 1279, DT 46, DWR 185 CG 1010 and MACS 3927 were found the promising genotypes with higher yield under irrigated (non-stressed) condition, while the genotypes MP 1279, DDG 30, DWR 185 and CG 1010 displayed the highest amount under stressed condition (Table 2). The low performing genotypes were BIJAGGA RED and NP 404 under non stressed condition and the genotypes N 59, HI 7483 and NP 404 under stressed condition (Table 2). It is interesting that the genotypes MP 1279 and DWR 185 and CG 1010 had high performances in both stressed and nonstressed conditions. Other wheat genotypes were identified as semi-tolerance or semisensitive to drought stress (Table 2). It is rare that one single genotype shows good performance in two different humidity conditions and finding such a genotype is good chance for plant breeders. Therefore, the genotypes MP 1279 and DWR 185 and CG 1010 are good candidates for commercial cultivation for farmers in both rainfed and irrigated regions. We found that the severe drought stress environment, ( $\mathrm{SI}=0.58)$ was less discriminative for some indices, e.g. STI, YSI and SDI. Severe drought stress causes reduction in metabolic activity rather than moderate drought stress (Ma et al., 2006; Naya et al., 2007). The grain yield reduction ranged between $12.58 \%$ and $76.18 \%$ in drought plots. This explains the substantial reduction in yield under severe drought stress for majority of genotypes (Table 2). Therefore, moderate drought stress environments may be preferred as compared to severe drought stress to identify drought tolerant lines. Based on the SSI, the genotypes DWR 185 (0.89), GW 2 (0.43), DDG 30 (0.68) and MP $1279(0.98)$ were identified as drought tolerance genotypes in stressed condition, while the genotypes MACS 3927 (1.26) and N 59 (1.29) displayed the highest amount of SSI (Table 2). Stress susceptibility index was negatively correlated with yield 
measured under drought stress. Stress susceptibility index could be used as selection index but only in combination with yield performance data under water-deficit conditions in order to identify droughttolerant genotypes with reasonable productivity. These findings concur with the findings of Kumar et al., (2016) in maize hybrids. According to the MP, the genotypes MP 1279 (14.60) DWR 185 (10.32) and DT 46(9.49) were found drought tolerance genotypes, and the genotypes NP 404 (4.03), BIJAGA RED (4.31) and MACS 9 (5.30) were identified as drought susceptible ones in stressed condition.

The other remained genotypes were identified as semi-tolerance or semi-sensitive to drought stress (Table 2). MP is based on the arithmetic means and therefore, it may have an upward bias due to a relatively larger difference between Ypi and Ysi (Zangi, 2005). Generally higher MP value is indicator of genotypes with higher yield potential. Whereas the geometric mean (GMP) is less sensitive to extreme values. GMP values recorded were highest in variety MP 1279 (5.39) followed by DWR 185 (4.50) and CG 1010 (4.41). A larger value of TOL show more sensitivity to stress, thus a smaller value of TOL is favored. Based on the TOL, the genotypes BIJAGA RED (0.58), GW 2(2.23), NP 404 (2.92), UAS 446 (3.81) and DDG 30 (4.43) were identified as drought tolerance genotypes. As there was lower reduction in yield under stress condition in comparison with well watered condition for these genotypes, but genotypes with lower TOL except DDG 30 were found low yielding under irrigated condition (Table 2). The higher STI values caused higher stress tolerance and yield potential (Rosielle and Hamblin, 1989). The highest values of STI was obtained for genotypes BIJAGA RED (0.87) followed by GW 2(0.75) DDG 30
(0.60) and UAS 446(0.58) (Table 2). Mevlut and Sait (2011) showed that genotypes with high STI values usually have high difference in yield in two different humidity conditions. They reported relatively similar ranks for the genotypes observed by GMP and MP parameters as well as STI, which suggests that these three parameters are equal for screening drought tolerant genotypes. The values of HM ranged from 3.505 (NP 404 to 12.16 (MP 1279). According to the harmonic mean (HM), the genotypes MP 1279 (12.16), DWR 185(8.68), DDG 30 (8.37) and CG $1010(8.24)$ were identified as drought tolerance genotypes, while the other remained genotypes showed the lower values of HM (Table 2).

The results of both GMP and HM indices were completely similar. It seems that this similarity is due to nature of their calculating formulas and so it is logical to use one of them in future studies. Results for MP and GMP were in accordance with the findings of Sahar et al., (2016). Based on the YI index, the genotypes MP 1279 (2.16), DWR 185 (1.58), DDG 30 (1.68), CG 1010 (1.48) and GW 2 (1.33) were identified as drought tolerance genotypes, while the genotypes $\mathrm{N}$ 59 (0.59) showed the lowest amount of YI and could be considered as drought susceptible genotype (Table 2); according to MSTIk1 and MSTIk2 MP1279, DWR 185, DT 46were found most stress tolerant genotypes, whereas NP 404, HI 7483 and N 59 were most relative sensitive genotypes to drought. Ilker et al., (2011) reported that STIrelated indices (K1STI and K2STI) are convenient parameters to select high-yielding genotypes in both stress and non-stress conditions. The lower SDI value confirms the tolerant genotypes and accordingly BIJAGA RED, DR 185, DDG 30.CG 1010, MP 1279 and HI 8751 could be considered as relatively tolerant genotypes. 
Table.1 Mean Square of $Y_{P}, Y_{S}$ and different drought tolerance indices in durum wheat

\begin{tabular}{|c|l|c|c|c|}
\hline $\begin{array}{c}\text { Sr. } \\
\text { No. }\end{array}$ & \multicolumn{1}{|c|}{ Drought tolerance indices } & $\begin{array}{c}\text { Replication } \\
(\mathbf{d f}=\mathbf{1})\end{array}$ & $\begin{array}{c}\text { Mean squares } \\
\text { treatment } \\
(\mathbf{d f}=\mathbf{1 9})\end{array}$ & $\begin{array}{c}\text { Error } \\
(\mathbf{d f} \\
\mathbf{1 9})\end{array}$ \\
\hline $\mathbf{1}$ & YP; Yield in non stress & 31.45 & 24.99 & 9.97 \\
\hline $\mathbf{2}$ & YS; Yield in stress condition & 8.10 & 5.45 & 0.52 \\
\hline $\mathbf{3}$ & SSI; Stress susceptible Index & 0.017 & $0.154 * *$ & 0.062 \\
\hline $\mathbf{4}$ & MP; mean productivity & 17.90 & $11.60^{*}$ & 2.96 \\
\hline $\mathbf{5}$ & TOL; Tolerance & 7.60 & 14.50 & 9.15 \\
\hline $\mathbf{6}$ & SDI ; Sensitivity drought Index & 0.016 & $0.052^{*}$ & 0.021 \\
\hline $\mathbf{7}$ & YSI; Yield susceptible Index & 0.016 & $0.052^{*}$ & 0.021 \\
\hline $\mathbf{8}$ & K STI; Modified stress tolerance index 1 & 0.017 & $1.39 * *$ & 0.42 \\
\hline $\mathbf{9}$ & K2 STI; Modified stress tolerance index 2 & 0.059 & $2.089 * *$ & 0.10 \\
\hline $\mathbf{1 0}$ & GMP ; Geometric mean productivity & 1.14 & $0.70^{* *}$ & 0.20 \\
\hline $\mathbf{1 1}$ & HM; Harmonic mean & 14.12 & $9.15^{* *}$ & 1.17 \\
\hline $\mathbf{1 2}$ & YI; Yield index & 0.008 & $0.34^{* *}$ & 0.034 \\
\hline $\mathbf{1 3}$ & STI; Stress tolerance index & 0.016 & $0.052^{*}$ & 0.021 \\
\hline
\end{tabular}

Table.2 Grain yield per plant (g) under well watered and drought regime with reduction in yield $(\%)$

\begin{tabular}{|l|r|r|r|}
\hline \multicolumn{1}{|c|}{ Genotype } & Well watered regime & Drought regime & Yield Reduction \% \\
\hline MACS 3927 & 12.29 & 3.21 & 73.87 \\
\hline DWR-185 & 14.29 & 6.35 & 55.57 \\
\hline BIJAGRA YELLOW & 8.79 & 3.55 & 59.61 \\
\hline N-59 & 9.78 & 2.33 & 76.18 \\
\hline BIJAGAA RED & 4.60 & 4.02 & 12.58 \\
\hline GW-2 & 7.58 & 5.35 & 29.46 \\
\hline DT 46 & 14.60 & 4.40 & 69.89 \\
\hline DDG 30 & 11.15 & 6.71 & 39.78 \\
\hline CG 1010 & 13.53 & 5.95 & 56.06 \\
\hline GW 1 & 10.05 & 3.82 & 61.98 \\
\hline UAS 446 & 9.04 & 5.23 & 42.15 \\
\hline MP 1279 & 20.53 & 8.67 & 57.77 \\
\hline NIDW 15 & 8.24 & 4.10 & 50.27 \\
\hline HI 8751 & 9.46 & 4.49 & 52.53 \\
\hline MACS 9 & 7.69 & 2.91 & 62.11 \\
\hline MACS 3916 & 9.36 & 3.44 & 63.27 \\
\hline HI 8754 & 9.84 & 3.24 & 67.06 \\
\hline HI 8627 & 9.65 & 2.83 & 70.64 \\
\hline NP 404 & 5.50 & 2.57 & 53.19 \\
\hline HI 7483 & 8.56 & 2.54 & 70.29 \\
\hline
\end{tabular}


Table.3 Mean values of different drought indices for tested durum wheat genotypes

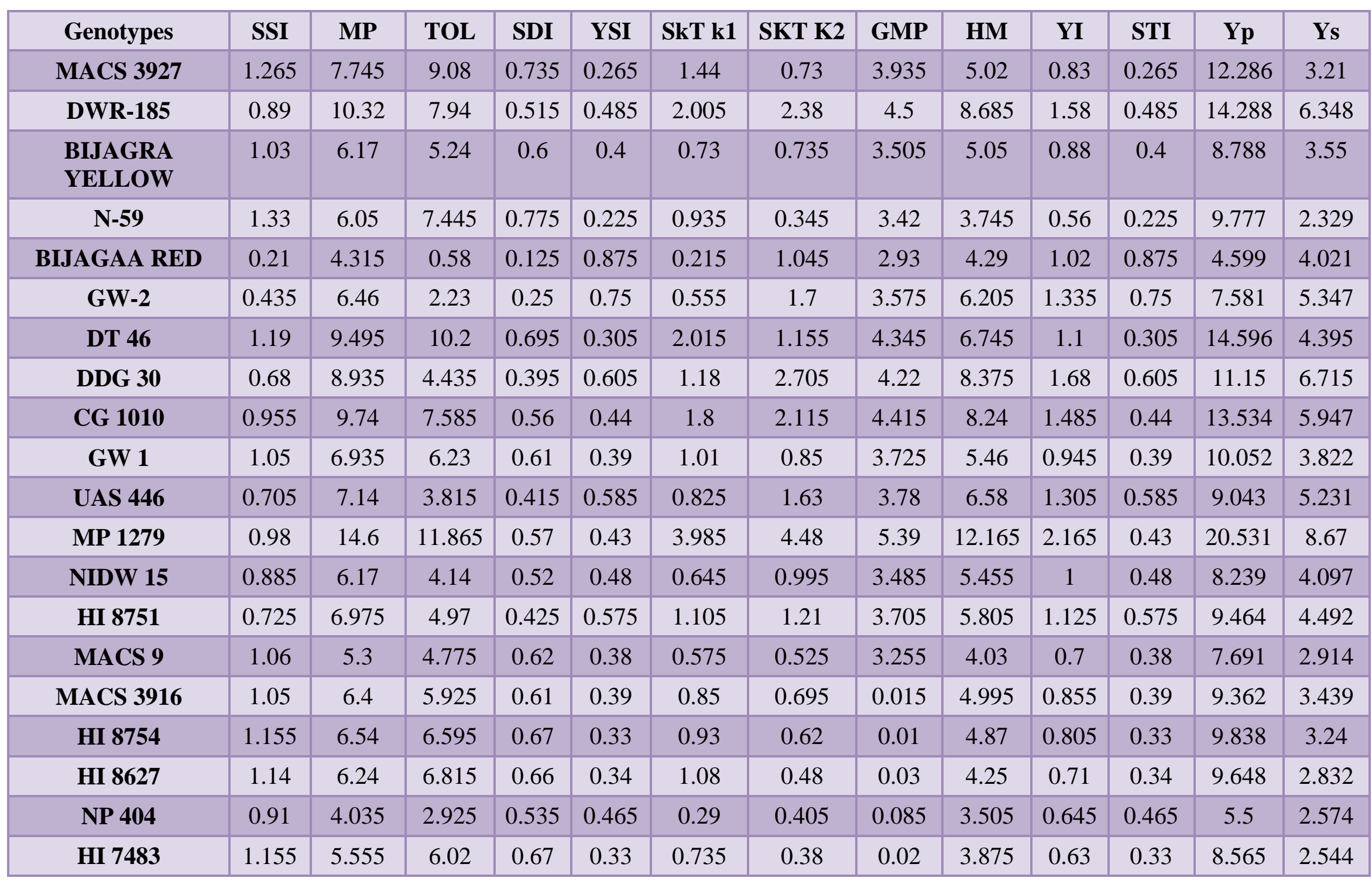


Table.4 Spearman rank correlation coefficients of Yp, Ys and eleven drought tolerance indices for the twenty durum wheat genotypes

\begin{tabular}{|c|c|c|c|c|c|c|c|c|c|c|c|c|c|}
\hline & SSI & MP & TOL & SDI & YSI & $\mathbf{K}_{1}$ & $\mathbf{K}_{2}$ & GMP & HM & YI & STI & $\mathbf{Y}_{\mathbf{P}}$ & $\mathbf{Y}_{\mathbf{S}}$ \\
\hline SSI & & & & & & & & & & & & & \\
\hline MP & $0.128^{\mathrm{NS}}$ & & & & & & & & & & & & \\
\hline TOL & $0.711^{\text {** }}$ & $0.753^{* *}$ & & & & & & & & & & & \\
\hline SDI & $1.000^{* * *}$ & $0.128^{\mathrm{NS}}$ & $0.709^{* *}$ & & & & & & & & & & \\
\hline YSI & $-1.000^{* *}$ & $-0.128^{\mathrm{NS}}$ & $-0.709^{* *}$ & $-1.000^{* * *}$ & & & & & & & & & \\
\hline $\mathbf{K}_{1}$ & $0.255^{\mathrm{NS}}$ & $0.965^{* *}$ & $0.841^{* *}$ & $0.253^{\mathrm{NS}}$ & $-0.253^{\mathrm{NS}}$ & & & & & & & & \\
\hline $\mathbf{K}_{2}$ & $-0.309^{\mathrm{NS}}$ & $0.874^{* *}$ & $0.360^{\mathrm{NS}}$ & $-0.307^{\mathrm{NS}}$ & $0.307^{\mathrm{NS}}$ & $0.787^{* *}$ & & & & & & & \\
\hline GMP & $0.144^{\mathrm{NS}}$ & $0.994^{* *}$ & $0.756^{* *}$ & $0.144^{\mathrm{NS}}$ & $-0.144^{\mathrm{NS}}$ & $0.942^{* *}$ & $0.850^{* *}$ & & & & & & \\
\hline HM & $-0.165^{\mathrm{NS}}$ & $0.945^{* *}$ & $0.502^{*}$ & $-0.164^{\mathrm{NS}}$ & $0.164^{\mathrm{NS}}$ & $0.855^{* *}$ & $0.972^{* *}$ & $0.936^{* *}$ & & & & & \\
\hline YI & $-0.398^{\mathrm{NS}}$ & $0.844^{* *}$ & $0.284^{\mathrm{NS}}$ & $-0.397^{\mathrm{NS}}$ & $0.397^{\mathrm{NS}}$ & $0.721^{* *}$ & $0.981^{* *}$ & $0.834^{* *}$ & $0.969^{\text {** }}$ & & & & \\
\hline STI & $-1.000^{* *}$ & $-0.128^{\mathrm{NS}}$ & $-0.709^{* *}$ & $-1.000^{* * *}$ & $1.000^{* *}$ & $-0.253^{\mathrm{NS}}$ & $0.307^{\mathrm{NS}}$ & $-0.144^{\mathrm{NS}}$ & $0.164^{\mathrm{NS}}$ & $0.397^{\mathrm{NS}}$ & & & \\
\hline $\mathbf{Y}_{\mathbf{P}}$ & $0.358^{\mathrm{NS}}$ & $0.968^{* *}$ & $0.894^{* *}$ & $0.357^{\mathrm{NS}}$ & $-0.357^{\mathrm{NS}}$ & $0.977^{* *}$ & $0.733^{* *}$ & $0.965^{* *}$ & $0.835^{\text {** }}$ & $0.683^{* *}$ & $-0.357^{\mathrm{NS}}$ & & \\
\hline $\mathbf{Y}_{\mathbf{S}}$ & $-0.392^{\mathrm{NS}}$ & $0.844^{* *}$ & $0.284^{\mathrm{NS}}$ & $-0.391^{\mathrm{NS}}$ & $0.391^{\mathrm{NS}}$ & $0.721^{* *}$ & $0.982^{* *}$ & $0.834^{* * *}$ & $0.970^{* *}$ & $1.000^{* *}$ & $0.391^{\mathrm{NS}}$ & $0.683^{* *}$ & \\
\hline
\end{tabular}


Table.5 Character loading of two principal components for twenty genotypes of durum wheat

\begin{tabular}{|l|l|l|}
\hline Genotypes & PC1 & PC2 \\
\hline MACS 3927 & -0.11993 & -2.80909 \\
\hline DWR-185 & 3.383183 & 0.165994 \\
\hline BIJAGRA YELLOW & -1.12675 & -0.44543 \\
\hline N-59 & -1.83869 & -2.97861 \\
\hline BIJAGAA RED & -1.89256 & 5.753328 \\
\hline GW-2 & 0.092085 & 4.216992 \\
\hline DT 46 & 1.71683 & -2.52898 \\
\hline DDG 30 & 2.530972 & 2.372529 \\
\hline CG 1010 & 2.725763 & -0.25712 \\
\hline GW 1 & -0.44615 & -0.7616 \\
\hline UAS 446 & 0.459582 & 2.08907 \\
\hline MP 1279 & 8.1747 & -1.08857 \\
\hline NIDW 15 & -0.85994 & 0.734868 \\
\hline HI 8751 & 0.072909 & 1.577267 \\
\hline MACS 9 & -2.05653 & -0.63735 \\
\hline MACS 3916 & -1.52615 & -0.8763 \\
\hline HI 8754 & -1.55564 & -1.70178 \\
\hline HI 8627 & -1.85269 & -1.72263 \\
\hline NP 404 & -3.37604 & 0.541969 \\
\hline HI 7483 & -2.50495 & -1.64454 \\
\hline
\end{tabular}

Abbreviations: SSI stress susceptible index; MP, mean productivity; TOL Tolerance; SDI; Sensitivity drought Index; YSI, yield susceptible index; MSTIk1, modified stress tolerance index 1; MSTIk2, modified stress tolerance index 2; GMP, geometric mean productivity; HM, harmony mean; YI, Yield index; STI, stress tolerance index;; $\mathrm{Y}_{\mathrm{p}}$; yield of each cultivars in non-stress condition, $Y_{s}$ yield of each cultivars, under stress condition

Fig.1 Biplot of first two principal component axes of drought tolerance indices in wheat

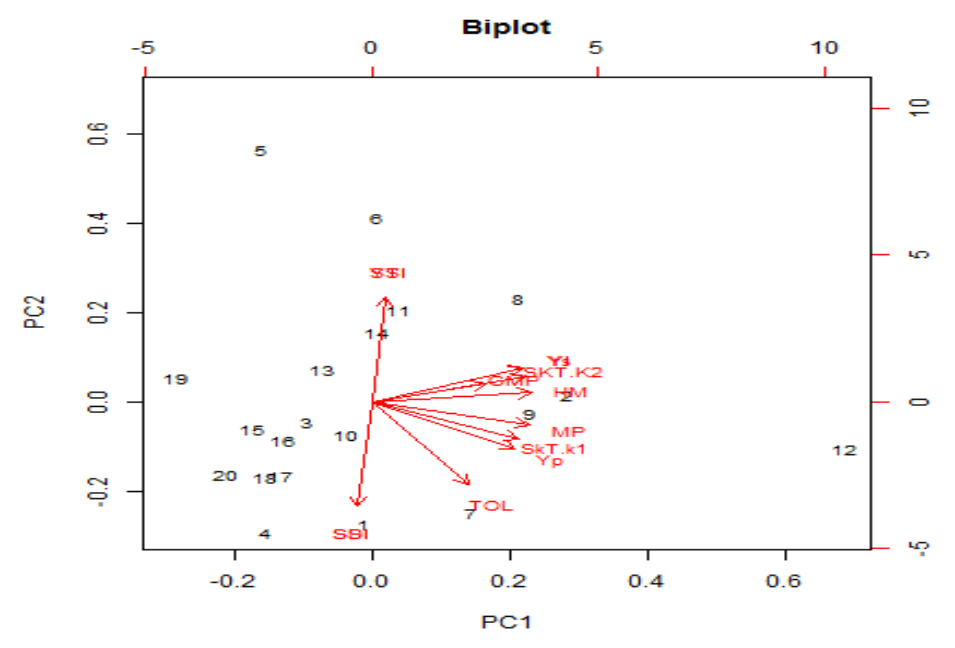




\section{Relationships between drought tolerance indices}

Correlation coefficients between grain yield and drought indices are presented in Table 4. Significantly positive correlation of $\mathrm{Yp}$ and Ys $\quad(r=0.68 \quad \mathrm{p}<0.05)$ was found which indicates that high yield performance under favorable condition resulted in relatively high yield under stress conditions. Both Yp and Ys were significantly and positively correlated $(\mathrm{P}<0.05)$ with, MP $(r=0.96$ and 0.84$)$, GMP $(r=0.96$ and 0.83$), \mathrm{HM}(r=0.83$ and 0.97$)$, YI $(r=0.68$ and 1.00), K1STI ( $r=0.97$ and 0.72$)$ and K2-STI ( $r=0.73$ and 0.98 ) (Table 4). This indicates that these indices were more effective in identifying high yielding lines under drought stress as well as non-stress conditions. The correlation between $Y s$ and either SSI or SDI was significant and negative $(r=-0.92)$. A positive correlation between irrigated yield (Yp) and SSI, TOL and a negative correlation between grain yield of drought stress (Ys) and SSI, TOL (Table 6) suggest that selection based on SSI and TOL will result in reduced yield under irrigated conditions. Especially, negative correlation between SSI and Ys was expected because genotypes that suffer less yield loss from irrigated to drought conditions also tend to have high yield in stress environments. SSI identified some genotypes such as BIJAGA RED, GW 2 and DWR 185 as stress resistant though they did not have outstanding yield performance in stress primarily because of their low potential yield (Table 3). On the other hand, the correlation between Yp and SSI was negligible $(r=0.35)$.The $Y s$ was significantly correlated $(\mathrm{P}<0.01)$ with all indices except SSI and TOL, where as $Y p$ was highly significantly correlated with only seven indices (TOL, MP, GMP, HM, YI, K1STI and K2-STI). Highly correlated indices with both the $Y s$ and $Y p$ are most appropriate for identifying stress tolerant cultivars (Farshadfar et al., 2011). The MP, GMP and
YI indices, which were highly positive and significantly correlated to the grain yields in both favorable and drought stress environments, were introduced as the best indices. These observed relationships are in consistence with numerous studies. Many studies reported positive relationships between Ys and the most popular and widely used indices MP, GMP, STI, SSI, TOL (Mohammadi et al., 2010; Farshadfar et al., 2012a). The SSI had positive association with MP, TOL and SDI, but had negative correlation with the YI and STI indices. Similarly, Ehdaie and Shakiba (1996) found no correlation between stress susceptibility index and yield under optimum condition.

The values of PC1 and PC2 are presented in table 5. Selection of genotypes that have high PCA1 and low PCA2 are suitable for both rain-fed and irrigated conditions. Therefore, MP 1279, CG 1010, DWR 185 and DT 46 are the superior genotypes for both drought and irrigated conditions with high PC1 and low PC2. The relationships among drought tolerance indices are graphically displayed in a plot of two first principal components (PC1 and PC2) analysis (Fig. 1). The first and second components justified $94.61 \%$ of the variations between criteria (54.47 and 40.14 $\%$ for PC1 and PC2, respectively). The PC1 mainly distinguishes the SDI indice from the other remained indices, and the $\mathrm{PC} 2$ distinguishes the YSI, SSI and TOL indices from the indices which related to each other based on the PC1 scores (Fig. 1). One of the interesting interpretations of this plot is that the cosine of the angle between the vectors of two indices approximates the correlation coefficient between them. The cosine of the angles does relatively translate into correlation coefficients, since the plot of principal components analysis does explain most of the variation in a data set. Therefore, it could be concluded that the GMP, HM, YI, K2-STI, and Ys indices are positively 
associated with each other (Fig. 1). Also, positive associations were observed between MP, K1-STI with Yp.

Selection of drought-tolerant lines should be well adopted to stress and non-stress conditions. In the present study, a high positive correlation was recorded between grain yield and the drought indices studied. In addition, we observed that MP, GMP and YI are the best indices for selecting droughttolerant lines. It was observed that genotypes MP 1279, DWR 185 and CG 1010 are equally produced high grain yield both in drought stress and in irrigated area. Based on principle component analysis it can be concluded that Ys can discriminate drought tolerant genotypes with high grain yield under stress condition. Moderate drought stress environments should be used for screening for drought-tolerant genotypes rather than severe drought stress environments. Therefore, plant breeders should pay attention to severity of drought stress when selecting drought-tolerant wheat lines.

\section{References}

Barreto, H, Edmeades, G, Chapman, S. and Crossa, J (1994) The alpha lattice design in plant breeding and agronomy: Generation and analysis. Training material, CIMMYT pp1-10.

Bennani S, Birouk A, Nsarellah N, Jlibene M and Ouabbou H (2016) Efficiency of selection indices in screening bread wheat lines combining drought tolerance and high yield potential. Journal of Plant Breeding and Crop Science Vol. 8(5), pp. 72-86.

Bidinger FR, Mahalakshmi V, Rao GDP (1987). Assessment of drought resistance in pearl millet (Pennisetum americanum (L) Leeke). I Factors affecting yields under stress. Aust. J. Agric. Res. 38:37.
Bishaw Z, Struik PC, Van Gastel AJG (2011). Wheat and barley seed system in Syria: farmers' varietal perceptions, seed sources and seed management. Int. J. Plant Prod. 5(4): 323.

Bouslama M, Schapaugh WT (1984). Stress tolerance in soybean. Part 1: Evaluation of three screening techniques for heat and drought tolerance. Crop Sci. 24:933

Bouslama M., Schapaugh W.T. (1984). Stress tolerance in soybeans. I. Evaluation of three screening techniques for heat and drought tolerance. Crop Science 24(5), 933-937.

Byrne P.F., Bolanos J., Edmeades G.O., Eaton D.L. (1995). Gains from selection under drought versus multilocation testing in related tropical maize populations. Crop Science, 35, 63-69.

Boussen H, Ben Salem M, Slama A, Mallek E, Rezgui S (2010). Evaluation of drought tolerance indices in durum wheat recombinant inbred lines. In: Lopez-Francos A. (Comp.), LopezFrancos A. (Collab.). Economics of drought and drought preparedness in a climate change context. Zaragoza: CIHEAM/FAO/ICARDA/GDAR/CEIG RAM/MARM. Options Méditerranéennes Série A, Séminaires Méditerranéennes: $\mathrm{N}^{\circ} 95$.

Dadbakhsh A, Yazdansepas A, Ahmadizadeh M (2011). Study drought stress on yield of wheat (Triticum aestivum L.) genotypes by drought tolerance indices. Adv. Envid. Biol. 5(7):1804-1810.

Dejan, D. Miroslav, Z., Desimier, K., Stephen, R. K., and Gordana, S.M. 2008. Genotype x environment interaction for wheat yield in different drought stress conditions and agronomic traits suitable for selection. Australian Journal of Agricultural Research, 59: 536-545.

Ehdaie B, Shakiba MR. 1996. Relationship of inter node specific weight and water- 
soluble carbohydrates in wheat. Cereal Research Communication. 24: 61-67.

Farshadfar E, Elyasi P (2012). Screening quantitative indicators of drought tolerance in bread wheat (T. aestivum) landraces. Pelagia Research Library. Eur. J. Exp. Biol. 2(3):577.

Farshadfar E, Farshadfar M, Dabiri S (2012a). Comparison between effective selection criteria of drought tolerance in bread wheat landraces of Iran. Ann. Biol. Res. 3(7):3381.

Farshadfar E, Javadinia J (2011). Evaluation of chickpea (Cicer arietinum L.) genotypes for drought tolerance. Seed and Plant Improv. J. 27(4):517.

Farshadfar E, Pour SMM, Pour AAR (2012b). Repeatability of drought tolerance indices in bread wheat genotypes. Int. J. Agric. Crop Sci. 4(13): 891.

Farshadfar E, Sheibanirad A, Soltanian M (2014). Screening landraces of bread wheat genotypes for drought tolerance in the field and laboratory. Int. J. Farm. Allied Sci. 3(3):304.

Farshadfar E., Sutka J. (2002). Screening drought tolerance criteria in maize. Acta Agronomica Hungarica 50, 411-416.

Fernandez GCJ (1992). Effective selection criteria for assessing plant stress tolerance. In: Kuo CG, ed. Adaptation of Food Crops to Temperature and Water Stress. Shanhua: Asian Vegetable Research and Development Center. Taiwan Publication 93(410):257.

Fischer R.A., Maurer R. (1978). Drought resistance in spring wheat cultivars. I. Grain yield responses. Crop and Pasture Science 29, 897-912.

Fischer RA, Maurer R (1978). Drought resistance in spring wheat cultivars. Aust. J. Agric. Res. 29:897-912.

Fischer RA, Wood JT (1979) Drought resistance in spring wheat cultivars. III. Yield association with morphological traits. Australian Journal of
Agricultural Research 30, 1001-1020.

Gavuzzi, P., F. Rizza, M. Palumbo, R.G. Campaline, G.L. Ricciardi and B. Borghi. 1997. Evaluation of field and laboratory predictors of drought and heat tolerance in winter cereals. Can. J. Plant Sci., 77: 523-531.

Gholipouri, A., M. Sedghi, R.S. Sharifi and N.M. Nazari. 2009. Evaluation of drought tolerance indices and their relationship with grain yield in wheat cultivars. Recent Res. Sci. Technol., 1(4): 195-198.

Golabadi, M., A. Arzani, and S.A.M.M. Maibody. 2006. Assessment of drought tolerance in segregating populations in durum wheat. Afri. J. Agric. Res., 1(5): 162-171.

Hall, A.E. 1993. Is dehydration tolerance relevant to genotypic differences in leaf senescence and crop adaptation to dry environments? In: Plant Responses to cellular dehydration during environmental stress. (Eds.): T.J. Close and E.A. Bray, pp. 1-10.

İlker E, Tatar Ö, Aykut Tonk F, Tosun M, Turk J (2011). Determination of Tolerance Level of Some Wheat Genotypes to Post-Anthesis Drought. Turkish J. Field Crops 16(1):59-63.

Johnson, H.W., H.F. Robinson and R.E Comstock. 1955. Genotypic and phenotypic correlations in soybean and other implications in selection. Agron. J., 47: 477-483.

Kristin, A.S, R.R. Senra, F.I. Perez, B.C. Enriquez, J.A.A. Gallegos, P.R. Vallego, N. Wassimi and J.D. Kelley. 1997. Improving common bean performance under drought stress. Crop Sci., 37: 43-50.

Kumar B, Guleria S K , Khanorkar S M., Dubey R B, Patel Jashvantlal , Kumar V. Parihar C M

Jat.S L Singh Vishal Yatish, K. R., Das Abhijit, Sekhar J. C, Bhati Pradeep, 
Kaur Harpreet, Kumar M, Singh A K , Varghese E., and Yadav $O P$, (2016). Selection indices to identify maize (Zea mays L.) hybrids adapted under drought-stress and drought-free conditions in a tropical climate. Crop \& Pasture Science http://dx.doi.org/ 10.1071/CP16141.

Lan J. (1998). Comparison of evaluating methods for agronomic drought resistance in crops. Acta Agric Borealioccidentalis Sinica 7, 85-87

Lin, C.S., M.R. Binns and L.P. Lefkovitch, 1986. Stability analysis: where do we stand? Crop Sci., 26: 894-900.

Ma Q.Q., Wang W., Li Y.H., Li D.Q., Zou Q. (2006). Alleviation of photoinhibition in drought-stressed wheat (Triticum aestivum) by foliar-applied glycinebetaine. Journal of Plant Physiology 163, 165-175.

Mardeh A.S.S., Ahmadi A., Poustini K., Mohammadi V. (2006). Evaluation of drought resistance indices under various environmental conditions. Field Crops Research 98, 222-229.

Mevlüt A, Sait Ç (2011). Evaluation of drought tolerance indices for selection of Turkish oat (Avena sativa L.) landraces under various environmental conditions. Zemdirbyste Agric. 98(2):157-166.

Mitra J (2001). Genetics and genetic improvement of drought resistance in crop plants. Curr. Sci. 80:758

Mohammadi R, Armion M, Kahrizi D, Amri A (2010). Efficiency of screening techniques for evaluating durum wheat genotypes under mild drought condition. Int. J. Plant Prod. 4(1):11

Mohammadi R., Armion M., Kahrizi D., Amri A. (2010). Efficiency of screening techniques for evaluating durum wheat genotypes under mild drought conditions. Journal of Plant Production $4,11-24$
Naya L., Ladrera R., Ramos J., Gonzalez E.M., Arrese-Igor C., Minchin F.R., Becana M. (2007). The response of carbon metabolism and antioxidant defenses of alfalfa nodules to drought stress and to the subsequent recovery of plants. Plant Physiology 144, 11041114.

Nouri A, Etminan A, Teixeira da Silva JA, Mohammadi R (2011). Assessment of yield, yield-related traits and drought tolerance of durum wheat genotypes (Triticum turjidum var. durum Desf.). Aust. J. Crop Sci. 5(1):8-16.

Pirayvatlou A.S. (2001). Relations among yield potential, drought tolerance and stability of yield in bread wheat cultivars under water deficit conditions. Proceedings of the 10th Australian Agronomy Conference. Hobart, January 29, 2001

Rosielle, R., A.A. and J. Hamblin. 1981. Theoretical aspects of selection for yield in stress and non- stress environment. Crop Sci., 21: 943-946.

Rajaram S., Braun H.J., Van Ginkel M. (1996). CIMMYT's approach to breed for drought tolerance. Euphytica 92, 147-153.

Rajaram S., Van Ginkle M. (2001). Mexico, 50 years of international wheat breeding. Bonjean. A.P., Angus W.J., (Eds.) The world wheat book: A history of wheat breeding. Lavoisier Publishing, Paris, France, 579-604.

Rosielle A.A., Hamblin J. (1981). Theoretical aspects of selection for yield in stress and non-stress environment. Crop Science 21, 943-946.

Sio-Se Mardeh A, Ahmadi A, Poustini K, Mohammadi V (2006). Evaluation of drought resistance indices under various environmental conditions. Field Crops Res. 98(2-3): 222-229.

Steel, SS, R.G.D. and J.H. Torrie. 1980. Principles and procedures of statistics: 
A biometrical approach. $2^{\text {nd }}$.ed. $\quad$ competitive wheat cultivars. Int. J. McGraw Hill Book Co., New York. Plant Prod. 6:1-14.

Talebi R., Fayaz F., Naji A.M. (2009) Effective selection criteria for assessing drought stress tolerance in durum wheat (Triticum durum DESF.). General and Applied Plant Physiology, 35, 64-74.

Zangi, M.R. 2005. Correlation Between Drought Resistance Indices and Cotton Yield in Stress and Non Stress Conditions. Asian Journal of Plant Sciences, 4: 106-108.

Travlos IS (2012). Reduced herbicide rates for an effective weed control in

\section{How to cite this article:}

Patel, J.M., A.S. Patel, C.R. Patel, H.M. Mamrutha, Sharma Pradeep and Karen P. Pachchigar. 2019. Evaluation of Selection Indices in Screening Durum Wheat Genotypes Combining Drought Tolerance and High Yield Potential. Int.J.Curr.Microbiol.App.Sci. 8(04): 1165-1178. doi: https://doi.org/10.20546/ijcmas.2019.804.134 